\title{
Deep Level Transient Spectroscopy of AlGaInP LEDs
}

\author{
M. Atiq1,2, Nazir A. Naz1, Akbar Ali1,2 \\ ${ }^{1}$ Department of Applied Physics, Federal Urdu University of Arts, Science and Technology, Islamabad, Pakistan \\ ${ }^{2}$ Department of Basic Sciences, Riphah International University, Islamabad, Pakistan \\ Email: aarandhawa@yahoo.com, Nazir Phys@yahoo.com
}

Received 8 October 2014; revised 5 November 2014; accepted 1 December 2014

Copyright (C) 2014 by authors and Scientific Research Publishing Inc.

This work is licensed under the Creative Commons Attribution International License (CC BY).

http://creativecommons.org/licenses/by/4.0/

c) (i) Open Access

\begin{abstract}
Deep level transient spectroscopy (temperature scans) of AlGaInP based red light emitting diodes was carried out from $77 \mathrm{~K}$ to room temperature. At least ten defects were observed. Of these, five defects assigned to energy states $0.21,0.22,0.24,0.26$, and $0.24 \mathrm{eV}$ were characterized. Respective capture cross-sections, measured at infinite temperature $(T=\infty)$, were found to be $8.84 \times 10^{-16}$, $6.98 \times 10^{-16}, 7.86 \times 10^{-16}, 9.9 \times 10^{-16}$ and $2.1 \times 10^{-16} \mathrm{~cm}^{2}$. Corresponding concentrations of defects were $3.7 \times 10^{13}, 3.5 \times 10^{13}, 3.2 \times 10^{13}, 3.3 \times 10^{13}$ and $3.1 \times 10^{13} \mathrm{~cm}^{-3}$.
\end{abstract}

\section{Keywords}

\section{Semiconductors, MOCVD, Defects, DLTS}

\section{Introduction}

Recently a variety of light emitting diodes (LEDs), based on compound semiconductors have attracted considerable attention due to their structural versatility and unique properties [1] [2] such as high brightness and directionality, improved daytime visibility of various commercial outdoor displays, automobile indicators, traffic signals and use in high density external storage system [2]-[9]. AlGaInP based diodes, which emit wavelengths ranging from red to yellow green, are playing important role in the industry [1] [10] [11]. Although a high internal quantum efficiency has been achieved for AlGaInP based LEDs, however, external efficiency yet shows deterioration due to strong light absorption in GaAs substrate [1] [8] [9]. The main challenging issue is to improve the efficiency and the power loss of AlGaInP based LEDs.

To improve the luminescence and laser characteristics, it is very important to optimize the growth conditions of each layer of AlGaInP diodes. In general, growth conditions for semiconductor diodes (LEDs \& LDs) are determined by high resolution X-ray and photo luminescence (PL), however these techniques alone are in- 
sufficient for considering microscopic factors such as deep level defects that influence emission properties and laser performance [10] [12] [13]. Deep levels due to defects in AlGaInP materials act as non-radiative recombination and trapping centers, and significantly decrease the radiative efficiency and increase the thresh hold current density [10]. Study of defects in AlGaInP is, therefore, of great importance to improve the performance of the devices. In this article, we present a study of defects in AlGaInP, using Deep Level Transient Spectroscopy (DLTS).

\section{Samples}

Single color, high bright, low power consumption, highly reliable and long life light emitting diodes (LEDs) manufactured by Hebei IT, China [14] were imported. The diodes emit super bright red color (wavelength 632 $\mathrm{nm}$ ) under 2 volts (forward bias) and $20 \mathrm{~mA}$ current at $25^{\circ} \mathrm{C}$. The maximum reverse current at $25^{\circ} \mathrm{C}$ is $30 \mu \mathrm{A}$ under reverse voltage of 5 volts, suitable for DLTS measurements.

\section{Measurements}

Capacitance-voltage $(C-V)$ characteristics, shown in the inset of Figure 1, were measured at room temperature using capacitance meter, Boonton model 7200, [15]. $1 / C^{2}$ verses reverse bias plot is shown in Figure 1. Data was found to fit on two straight lines indicating almost uniform concentrations of acceptors and donors ( $N_{a}$ and $N_{d}$ ) in $n$ and $p$ sides of the PIN junction [16]. The concentrations were found to nearly same on both $p$ and $n$ sides of the junction.

After $C$ - $V$ measurements, DLTS [17] of the samples has been carried out with a very sensitive machine DLS83D, manufactured by Semitrap, Hungry [18]. This machine monitors emission of electrons or holes in depletion region of a junction. Temperature of the samples was decreased to $77 \mathrm{~K}$ by lowering the sample holder into liquid nitrogen container and increased with the help of a heater embedded in the holder during temperature scans. DLTS scans with different repetition rates were recorded using reverse voltage $V_{R}=3 \mathrm{~V}$ and filling pulse $t_{p}=500 \mu \mathrm{sec}$. Two typical temperature scans recorded with repetition rates of $5 \mathrm{~Hz}$ and $80 \mathrm{~Hz}$ are shown as spectrum (a) and (b) in Figure 2, respectively. In the case of PIN diodes, DLTS signal from both $n$ - and $p$ sides of the junction is possible, therefore, peaks, due to signals, can appear from either side of the junction. DLTS scans depict at least ten peaks named as P1, P2, P3, P4, P5, P6, P7, P8, P9, and P10, shown as spectrum (a) and (b) in Figure 2. Peak temperatures were noted for each scan and $\log \left(e / T^{2}\right)$ verses 1000/T was plotted corresponding to each peak on semi-log scale as shown in Figure 3. From the slopes and intercepts at $T=\infty$ of the best fit lines through the data points, activation energies and capture cross-sections, respectively, were calculated using the equation [17],

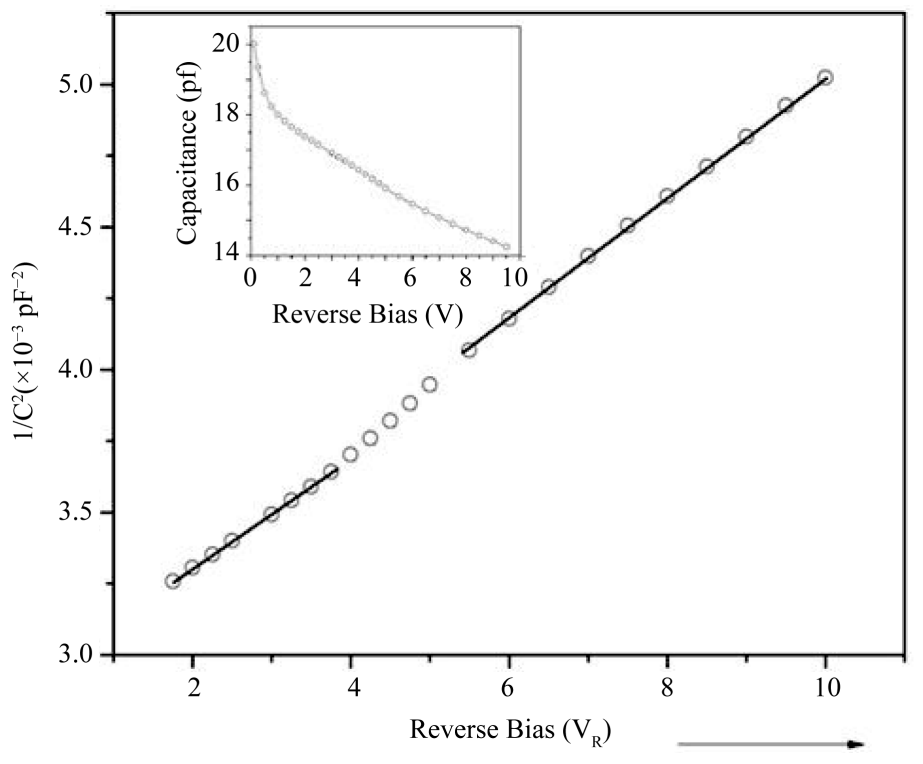

Figure 1. Caoacitance voltage characterisics of the samples. 


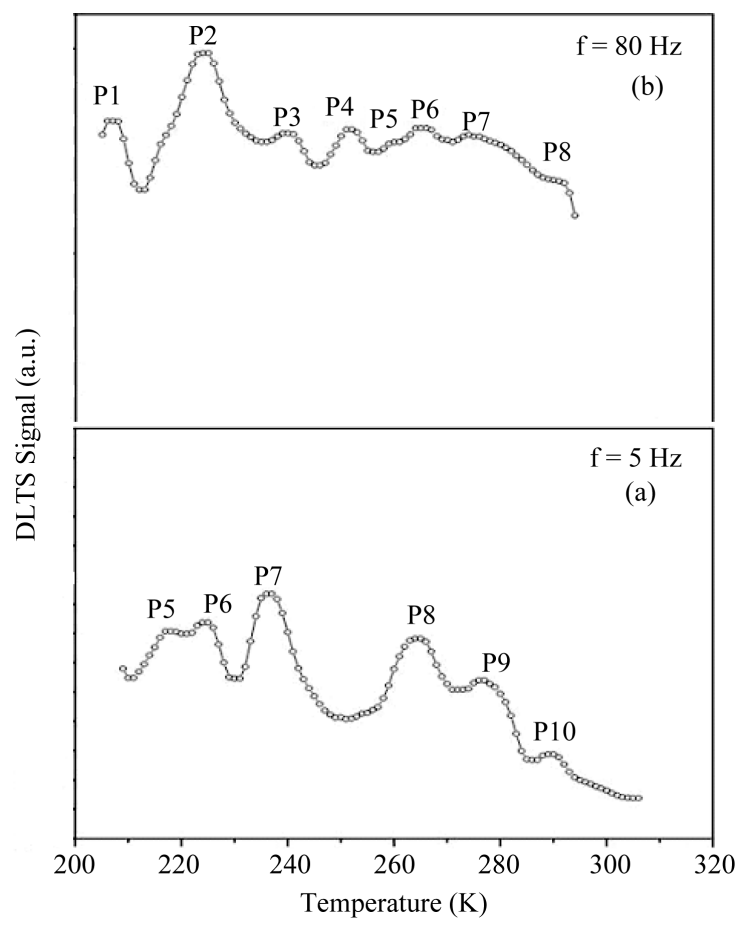

Figure 2. DLTS, temperature scans recorded at (a) $5 \mathrm{~Hz}$ and (b) $80 \mathrm{~Hz}$ of AlGaInP LEDs.

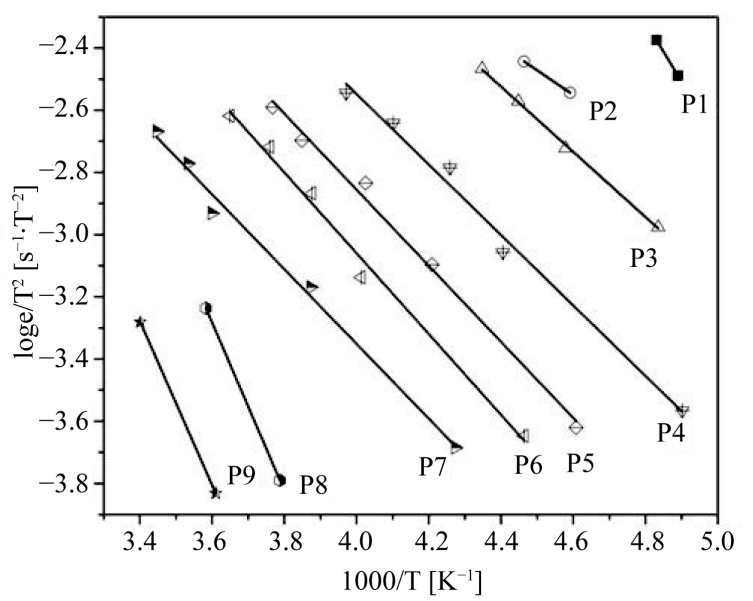

Figure 3. $T^{2}$ corrected Arrhenius plots of AlGaInP LEDs.

$$
e_{n, p}=g \sigma_{n, p n}\left\langle v_{t h}\right\rangle N_{c, v} \exp \left[-\left(E_{A}-T \Delta S\right) / k_{B} T\right]
$$

where, $e_{n, p}$ is the electron/hole emission rate at temperature $T, g$ is the degeneracy factor which, for simplicity, is taken as one, $\Delta S$ is the entropy change, $E_{A}$ is the thermal activation energy $\left(E_{T}-E_{V}\right)$ of the defect state, $\sigma_{n, p}$ the electron /hole capture cross section, $\left\langle v_{t h}\right\rangle$, the average thermal velocity of the electron/hole, $N_{c, v}$ the effective density of states in the conduction/valence band and $k_{B}$ the Boltzmann's constant.

\section{Results and Discussion}

At least ten peaks (P1-P10) were noticed in DLTS scans recorded using different repetition rates. Some of the peaks appear in scans recorded with lower repetition rate and others appear only in scans recorded with higher repetition rate. Only peaks, P5-P8, are observed consistently in all scans. Two typical scans recorded with 
Table 1. Characteristics of defects assigned to different peaks. $E_{A}, \sigma_{\infty}$ and $N_{T}$, represent thermal activation energy, apparent capture cross-section and concentration of deep levels, respectively.

\begin{tabular}{cccccc}
\hline Peaks & P3 & P4 & P5 & P6 & P7 \\
\hline$E_{A}(\mathrm{eV})$ & 0.21 & 0.22 & 0.24 & 0.26 & 0.24 \\
$\left(\sigma_{\infty}\right)\left(\times 10^{-19} \mathrm{~cm}^{-2}\right)$ & 1.1 & 0.87 & 0.98 & 1.2 & 0.26 \\
$N_{T}\left(\times 10^{13} \mathrm{~cm}^{-3}\right)$ & 3.7 & 3.5 & 3.2 & 3.3 & 3.1 \\
\hline
\end{tabular}

repetition rates of $5 \mathrm{~Hz}$ and $80 \mathrm{~Hz}$, shown in Figure 2(a) and Figure 2(b), respectively, are presented to show all peaks.

Only two data points could be recorded for peaks P1, P2, P8 and P9. Peak P10 appeared only in one scan taken with $80 \mathrm{~Hz}$ because our experimental setup did not allow to measure beyond room temperature. The appearances of the peaks P1 and P2 in higher frequency and P8 and P10 in lower frequency DLTS scans are quite natural. Calculations for thermal activation energies, capture cross-sections and concentrations of defects assigned to P1, P2, P8 and P10 are not reliable, therefore, not mentioned here. The activation energies obtained for the defects, P3-P7 are $0.21,0.22,0.24,0.26$ and $0.24 \mathrm{eV}$, and corresponding capture cross-sections calculated from the intercepts are $1.1 \times 10^{-19}, 8.7 \times 10^{-20}, 9.8 \times 10^{-20}, 1.2 \times 10^{-19}$ and $2.6 \times 10^{-20} \mathrm{~cm}^{2}$, respectively. The respective concentrations of the defects are $3.7 \times 10^{13}, 3.5 \times 10^{13}, 3.2 \times 10^{13}, 3.3 \times 10^{13}$ and $3.1 \times 10^{13} \mathrm{~cm}^{-3}$, respectively. The above data are also listed in Table 1.

Sugiura et al. [19] have reported three defects D1, D2 and D3 in MOVPE grown AlGaInP layer, corresponding to energies, $0.43,0.5$ and $1.3 \mathrm{eV}$, respectively. Among these, D3 was attributed to Aluminum related defect, while $\mathrm{D}_{1}$ and $\mathrm{D}_{2}$ were not identified. On comparison, it is found that our emission rate data do not show any matching to those reported by Sugiura et al. Byungjin et al. [8] detected a defect related peak corresponding to energy $0.2 \mathrm{eV}$ in their DLTS spectra of AlGaInP taken under two different ambient i.e. $\mathrm{H}_{2}$ and $\mathrm{N}_{2}$. While, Kim et al. [10] observed two DLTS peaks corresponding to energy states, $0.35-0.36$ and $0.48-0.5 \mathrm{eV}$ in their four multiple quantum well (MQW) structured AlGaInP samples grown by MOCVD. None of the emission rate data of our defects were found to similar with the above published data. Defects reported in our work are, therefore, different to those reported by other researchers. Most probably the defects are induced during growth either due to lattice mismatch or lattice imperfections or complexes formed due to high reactivity at atomic scale. These defects may act as radiative or non-radiative defects. If the defects act as a non-radiative recombination center [20], they will degrade the emission efficiency of the material. We doubt that among these defects few may act as such centers. For better emission output, such defects should be tightly controlled. As the material is relatively new, and the knowledge about the defects in this material is severely lacking in literature, DLTS study of the material is, therefore, of vital importance. Detailed work is in progress for obtaining a comprehensive picture of defects in the material.

\section{Acknowledgements}

DLTS measurements have been performed in Semiconductor Physics Laboratory, Quaid-i-Azam University, Islamabad, Pakistan.

\section{References}

[1] Kuo, D.-M., Wang, S.-J., Uang, K.-M., Chen, T.-M., Lee, W.-C. and Wang, P.-R. (2011) Applied Physics Express, 4, Article ID: 012101. http://dx.doi.org/10.1143/APEX.4.012101

[2] Lee, Y.-J., Lee, C.-J. and Chen, C.-H. (2011) Japanese Journal of Applied Physics, 50, Article ID: $04 D G 18$.

[3] Gessmann, Th. and Schubert, E.F. (2004) Journal of Applied Physics, 95, 2203. http://dx.doi.org/10.1063/1.1643786

[4] Lin, R.M., Li, J.C., Chou, Y.L. and Wu, M.C. (2006) IEEE Photonics Technology Letters, 18, 1642-1644. http://dx.doi.org/10.1109/LPT.2006.879524

[5] Krames, M.R., Shchekin, O.B., Regina, M.M., Mueller, G.O., Zhou, L., Harbers, G. and Craford, M.G. (2007) Journal of Display Technology, 3, 160-175. http://dx.doi.org/10.1109/JDT.2007.895339

[6] Lee, Y.J., Lu, T.C., Kuo, H.C. and Wang, S.C. (2007) Journal of Display Technology, 3, 118-125. http://dx.doi.org/10.1109/JDT.2007.894380 
[7] Lee, Y.J., Lin, P.C., Lu, T.C., Kuo, H.C. and Wang, S.C. (2007) Applied Physics Letters, 90, Article ID: 161115.

[8] Ma, B., Cho, S., Lee, C., Lee, S., Kang, J., Kim, B., Kang, D., Shin, Y., Kim, Y., Kim, T. and Park, Y. (1974) Japanese Journal of Applied Physics, 45, 774-777. http://dx.doi.org/10.1143/JJAP.45.774

[9] Yagi, T., Nishiguchi, H., Yoshida, Y., Miyashita, M., Sasaki, M., Sakamoto, Y., Ono, K.-I. and Mitsui, Y. (2003) IEEE Journal of Selected Topics in Quantum Electronics, 9, 1260. http://dx.doi.org/10.1109/JSTQE.2003.819514

[10] Kim, D.S., Kim, K.C., Shin, Y.C., Kang, D.H., Kim, B.J., Kimb, Y.M., Park, Y., Kim, T.G., Kim, D.S., et al. (2006) Physica B, 376-377, 610-613. http://dx.doi.org/10.1016/j.physb.2005.12.154

[11] Shima, A., Tada, H., Ono, K., Fujiwara, M., Utakouji, T., Kimura, T., Takemi, M. and Higuchi, H. (1997) IEEE Photonics Technology Letters, 9, 413-415. http://dx.doi.org/10.1109/68.559372

[12] Domen, K., Sugiura, K., Anayama, C., Kondo, M., Sugawara, M., Tanahashi, T. and Nakajima, K. (1991) Journal of Crystal Growth, 115, 529-532. http://dx.doi.org/10.1016/0022-0248(91)90799-B

[13] Kaniewska, M., Kryńska, D. and Wesołowski, M. (2001) Optical Materials, 17, 283-286. http://dx.doi.org/10.1016/S0925-3467(01)00093-3

[14] Data Sheet. Hebei International Trading (Shanghai) Co., Ltd.

[15] Instruction Manual, Capacitance-Meter, Boonton 7200. Boonton Electronics Corporation, Boonton.

[16] Tsarova, T., Wosinski, T., Kosa, A.M., Skierbiszewski, C., Grzegory, I. and Perlin, P. (2007) Acta Physica Polonica A, 112, 331-337.

[17] Lang, D.V. (1974) Journal of Applied Physics, 45, 3023. http://dx.doi.org/10.1063/1.1663719

[18] Operating Manual, Deep Level Transient Spectrometer, Serni Lab “DLS-83D”, Meunipex, Budapest, 1981.

[19] Sugiura, K., Domen, K., Sugawara, M., Anayama, C., Kondo, M., Tanahashi, T. and Nakajima, K. (1991) Journal of Applied Physics, 70, 4946-4949.

[20] Shin, Y.C., Kang, D.H., Kim, B.J., Lee, C.Y., Ma, B.J., Kang, J.S., et al. (2007) Journal of the Korean Physical Society, 50, 866. http://dx.doi.org/10.3938/jkps.50.866 
Scientific Research Publishing (SCIRP) is one of the largest Open Access journal publishers. It is currently publishing more than 200 open access, online, peer-reviewed journals covering a wide range of academic disciplines. SCIRP serves the worldwide academic communities and contributes to the progress and application of science with its publication.

Other selected journals from SCIRP are listed as below. Submit your manuscript to us via either submit@scirp.org or Online Submission Portal.
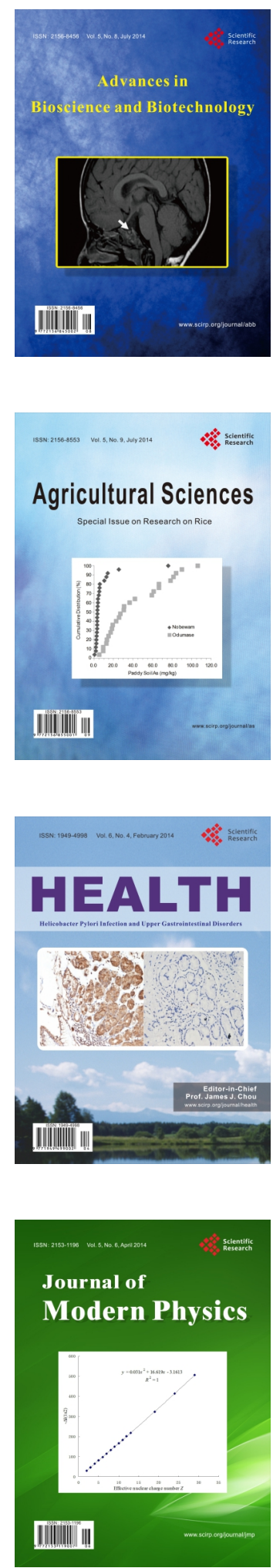
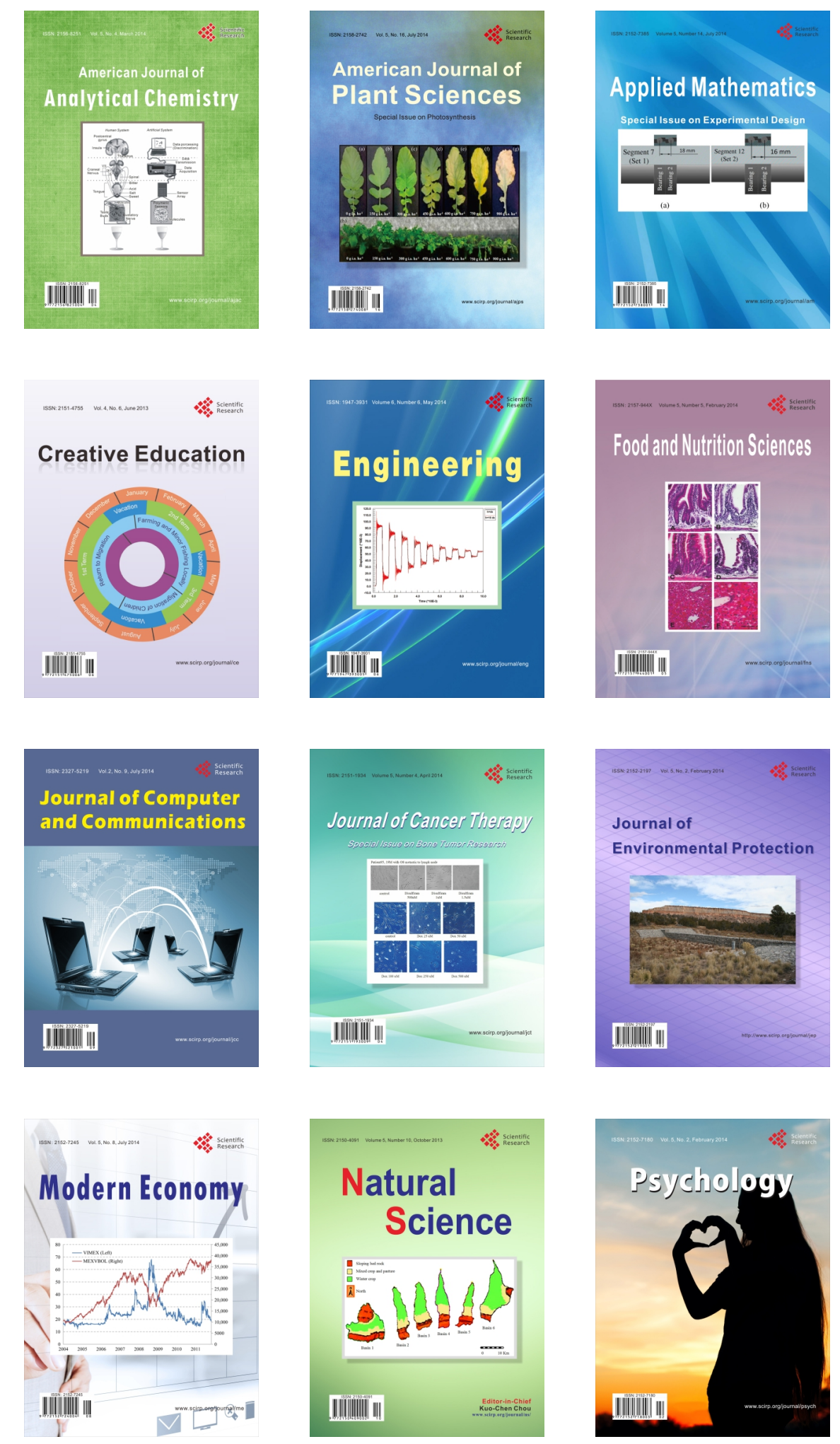